\title{
Cyclic Strain Stimulates Early Growth Response Gene Product 1-Mediated Expression of Membrane Type 1 Matrix Metalloproteinase in Endothelium
}

\author{
Seiichi Yamaguchi, Miho Yamaguchi, Eiji Yatsuyanagi, Sang-Soeb Yun, \\ Nobuyuki Nakajima, Joseph A. Madri, and Bauer E. Sumpio \\ Departments of Surgery (SY, MY, EY, S-SY, NN, BES) and Pathology (JAM), Yale University School of Medicine, \\ New Haven, and Department of Surgery, Veterans Affairs Medical Center, West Haven, Connecticut; and First \\ Department of Surgery (SY, MY, NN), Chiba University School of Medicine, Chiba, Japan
}

\begin{abstract}
SUMMARY: Matrix metalloproteinases (MMPs) are hypothesized to be involved in the processes of endothelial cell (EC) migration and matrix remodeling during angiogenesis. Although hemodynamic forces (such as blood pressure, wall tension, and shear stress) are considered to be strong stimuli for angiogenesis, the role of hemodynamic forces on the regulation of MMPs including membrane type 1 matrix metalloproteinase (MT1-MMP) has not been fully elucidated. To study this, rat microvascular EC were exposed to 60 cycles/minute of $24 \%$ maximum strain for up to 24 hours. MT1-MMP mRNA and protein increased in a time-dependent manner through 24 hours of exposure to cyclic strain. Cyclic strain induced early growth response gene product (Egr-1) mRNA and protein within 1 hour. A specific nucleoprotein complex was formed when an oligonucleotide containing binding sites for Sp1 and Egr-1 was incubated with nuclear extracts from EC exposed to 1 hour of cyclic strain. Antibodies to Egr-1 completely supershifted this complex. Increased binding of Egr-1 by cyclic strain to the MT1-MMP promoter correlated with enhanced transcriptional activity. These results suggest that cyclic strain up-regulates the Egr-1-mediated expression of MT1-MMP in rat microvascular EC, emphasizing the importance of hemodynamic forces in the regulation of MT1-MMP in vivo. (Lab Invest 2002, 82:949-956).
\end{abstract}

$M$ icrovascular endothelial cells (EC) actively remodel the extracellular matrix of basement membranes and mature interstitial tissues. Angiogenesis, which is the formation of new blood vessels from preexisting ones, is a critical component of the adaptations that occur in response to chronic increases in metabolic activity within tissues or tumors (Hanahan and Folkman, 1996; Pepper, 1997). The sprouting EC must break through their existing basement membranes and form contacts with and migrate along different extracellular matrix components, finally establishing new, patent microvessels (Pepper, 1997).

The matrix metalloproteinases (MMPs) are a gene family of enzymes with varied substrate specificity, ranging from multiple extracellular matrix components to cytokines, growth factors, and adhesion molecules (Matrisian, 1990; Woessner, 1994). Production and activation of MMPs correlate strongly with migratory and invasive behavior in many cell types, including

DOI: 10.1097/01.LAB.0000020408.77307.E9

Received March 28, 2002

This study was supported by grants from the National Heart, Lung, and Blood Institute (ROI HL-54732 to BES and RO1 HL-51018 to JAM) and the Veterans Affairs Merit Review (BES).

Address reprint requests to: Dr. Bauer E. Sumpio, Department of Surgery (Vascular), Yale University School of Medicine, 333 Cedar Street, FMB 137, New Haven, CT 06510.E-mail: bauer.sumpio@yale.edu endothelium (Birkedal-Hansen, 1995; Mignatti and Rifkin, 1996). For invasive tumor cells and stromal cells, membrane-type matrix metalloproteinases (MTMMPs) seem to link active proteinases to cell surfaces (Sato and Takino, 1994; Strongin et al, 1995). MTMMPs, which contain a membrane-spanning domain, play a unique role compared with secreted MMPs because their cell membrane location focuses extracellular matrix proteolysis on the cell surface and other specific subdomains of the cell surface, such as the leading edge of a migrating cell (Nakahara et al, 1997). Proteolysis of capillary basement membrane proteins by MMPs is a critical component of physiologic activity-induced angiogenesis in skeletal muscle (Haas et al, 2000).

It is known that hemodynamic forces, including mechanical cyclic strain and fluid shear stress, can modulate the expression of various genes in EC (Davies et al, 1997; Sumpio, 1993). Hemodynamic forces, which have been found to elicit a wide range of phenotypic responses both in intact tissues and in cultured cells, are likely involved in the activation of MMP because they are strong stimuli for vascular remodeling in vivo (Allen et al, 1996; Osol, 1995). However, there is scant information on the regulation of MT1-MMP in EC exposed to cyclic strain.

In this study, we demonstrated that expression of early growth response gene product (Egr-1) is regulated by cyclic strain in a unique temporal fashion and 
that the increased level of Egr-1 in strained cells results in enhanced expression of MT1-MMP.

\section{Results}

\section{Orientation of Microvascular EC on Collagen I}

Cell orientation is one of the important parameters when examining the responsiveness of EC to cyclic strain. It has been previously reported that EC harvested from different vascular beds react differently to the same cyclic strain regimen (Iba et al, 1991). This study is the first report on the response of microvascular EC to cyclic strain. We observed a change in the orientation from a random appearance to an alignment perpendicular to the force vector (Sumpio et al, 1988) (Fig. 1). The direction of the stretch vector is from periphery to center. Control EC that are grown on the flexible membrane under stationary conditions maintain random orientation. After 2 hours of cyclic strain, some cells start to align perpendicular to the strain force vector and become elongated. More cells elongate by 12 hours, and by 24 hours of cyclic strain, nearly all of the EC are elongated and aligned.

\section{Cyclic Strain Up-Regulates MT1-MMP mRNA and Protein in Rat Microvascular EC}

Strained EC increased their MT1-MMP mRNA levels, as assessed by Northern blot analysis, in a time- dependent manner until 24 hours of exposure to cyclic strain (Fig. 2A). This rise in MT1-MMP mRNA reached maximum levels of $2.7 \pm 0.4$-fold more than control value at 24 hours of exposure to cyclic strain (mean \pm SEM, $n=5$; Fig. 2B). MT1-MMP protein expression, as measured by Western blot analysis, was barely detectable under control conditions, but it was increased in a time-dependent manner upon exposure of EC to cyclic strain for 4 hours (Fig. 3).

\section{Cyclic Strain Up-Regulates Egr-1 mRNA and Protein in Rat Microvascular EC}

It has been demonstrated that Egr-1 is activated by multiple pathophysiologic stimuli and plays a positive regulatory role in the inducible expression of several endothelial genes. It has been shown that MT1-MMP transcription induced by an alteration in extracellular matrix environment occurs as a consequence of increased production and promoter binding of the transcription factor Egr-1 (Haas et al, 1999). Steady-state levels of mRNA and protein for Egr-1 were determined after exposure to cyclic strain for 0.5 to 10 hours for Northern blots, and for 0.5 to 48 hours for Western blots. Cyclic strain dramatically induced expression of Egr-1 mRNA, which peaked at 30 to 60 minutes of exposure (Fig. 4A). Egr-1 mRNA levels then decreased nearly to basal levels by 2 hours (Fig. 4A). In parallel, there was a rapid increase in Egr-1 protein levels,

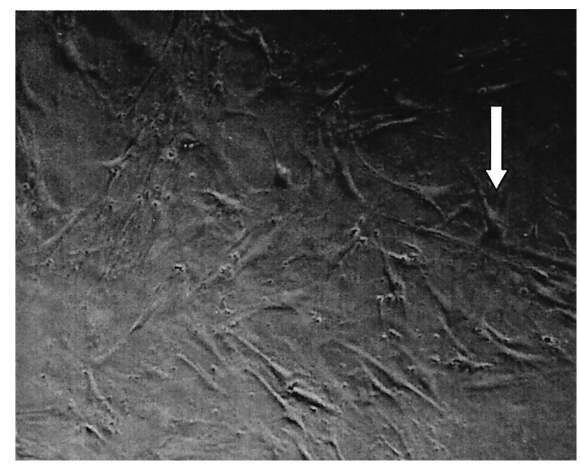

Control

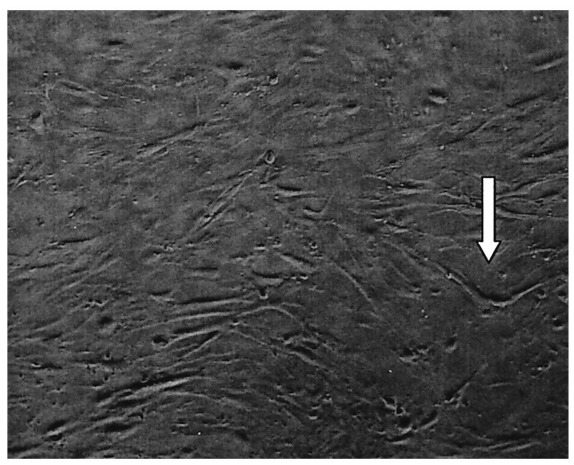

$8 \mathrm{~h}$

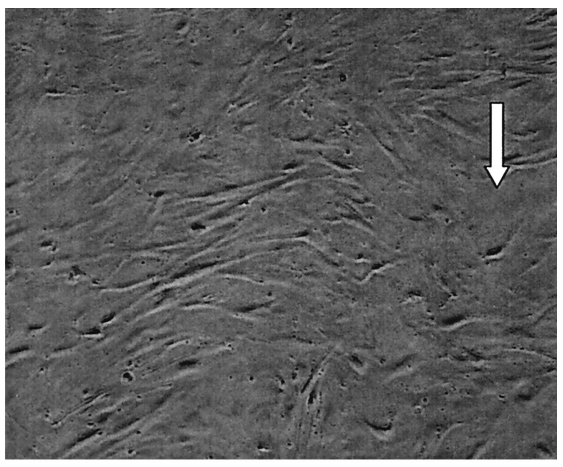

$2 \mathrm{~h}$

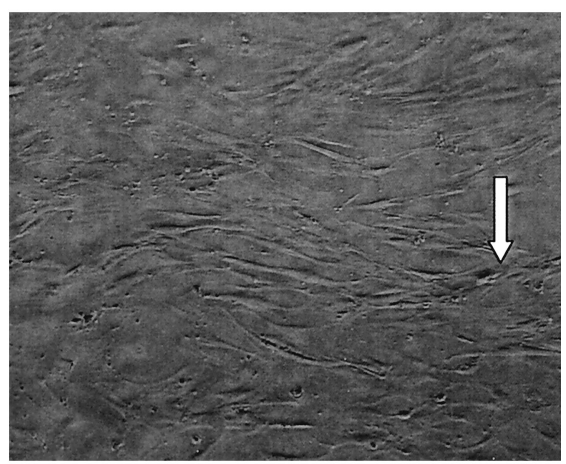

$24 \mathrm{~h}$

Figure 1.

Microvascular endothelial cell (EC) orientation at varying times of exposure to cyclic strain. EC were exposed to 60 cycles per minute, $24 \%$ elongation-relaxation for various time intervals. The top portion of the photographs represents the periphery of the membrane bottom, while the bottom portion represents the center of the membrane (magnification $\times 100$ ). 
A

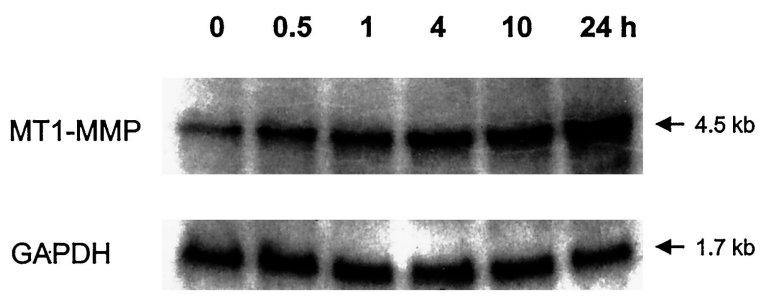

B

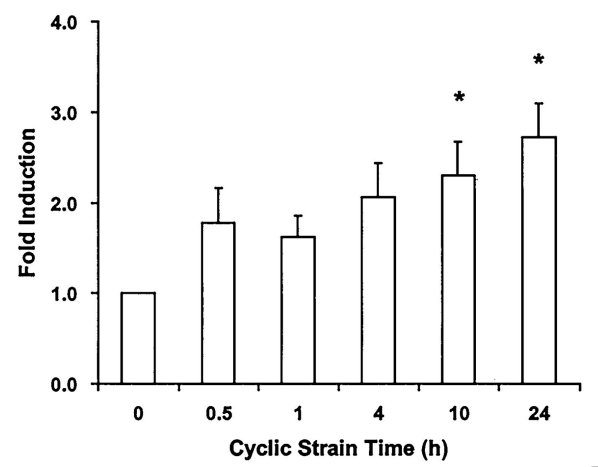

Figure 2.

Membrane type 1 matrix metalloproteinase (MT1-MMP) Northern blot analysis. A, Total RNA (10 or $15 \mu \mathrm{g}$ ) from rat microvascular EC exposed for $0,0.5$, $1,4,10$, and 24 hours was resolved on $1 \%$ formaldehyde/agarose gels and transferred to nylon membranes before hybridization with ${ }^{32} \mathrm{P}$-labeled $c$ DNA probes encoding human MT1-MMP. Blots were stripped and reprobed with a glyceraldehyde-3-phosphate dehydrogenase probe (GAPDH) probe to normalize for RNA loading. B, Images from panel A were densitometrically scanned and values were normalized to GAPDH and expressed as fold increase relative to unstrained cells. Results are mean \pm sEM from five different experiments. ${ }^{*} p$ $<0.05$ versus unstrained cells.
A

Egr-1

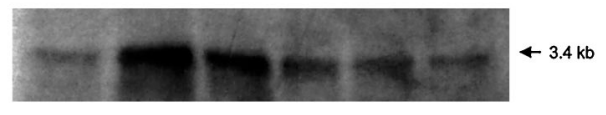

GAPDH

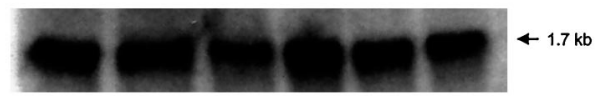

B

Egr-1

$\begin{array}{lllllll}0 & 0.5 & 1 & 4 & 10 & 24 & 48 h\end{array}$

$\alpha-$ Actin

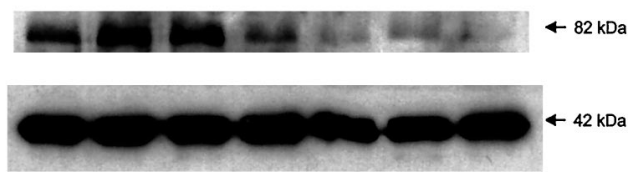

\section{Figure 4.}

Early growth response gene product (Egr-1) Northern and Western blots. A, Cyclic strain induced a rapid up-regulation of the Egr-1 mRNA levels in rat microvascular EC. GAPDH was used to normalize loading for total RNA loaded.

$B$, Cyclic strain induced a rapid up-regulation of Erg-1 protein levels in rat microvascular EC, using $\alpha$-actin to normalize for protein loading.

porter gene encoding luciferase. Comparison was made between the transcriptional activity of unstrained EC and that of strained EC. EC exposed to cyclic strain increased promoter activity of full-length MT1-MMP-luciferase and MT1-MMP(-300)luciferase but failed to increase promoter activity of MT1-MMP(-220)-luciferase (Fig. 5). Within the region between -300 and -220 lies a GC-rich sequence $(-288$ to -275$)$ that contains overlapping consensus binding sites for Sp1 and Egr-1. The above findings indicate that Egr-1/Sp1 binding sites contribute to the induction of MT1-MMP in EC exposed to cyclic strain.

$\begin{array}{lllllll}0 & 0.5 & 1 & 4 & 10 & 24 & 48 \mathrm{~h}\end{array}$

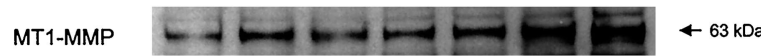

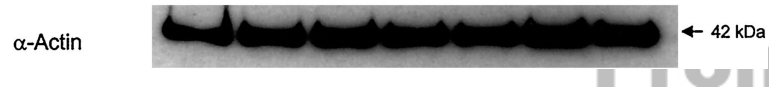

Figure 3.

MT1-MMP Western blot analysis. MT1-MMP protein levels were assessed in rat microvascular EC exposed for $0,0.5,1,4,10,24$, and 48 hours, using $\alpha$-actin to normalize for protein loading.

which seemed to peak approximately 1 hour after the initiation of cyclic strain (Fig. 4B). The earlier appearance of Egr-1 message and protein, followed by the induction of MT1-MMP message and protein, is consistent with the induction of a transcription factor before the maximal induction of the responding gene.

\section{MT1-MMP Transcriptional Activity in Static and Strained EC}

Transcriptional activity of the MT1-MMP promoter region was assessed in EC using full-length and truncated promoter sequences coupled to the re-
Ratio of strain/static $0.7 \quad$ l. $3 \quad$ 1.9

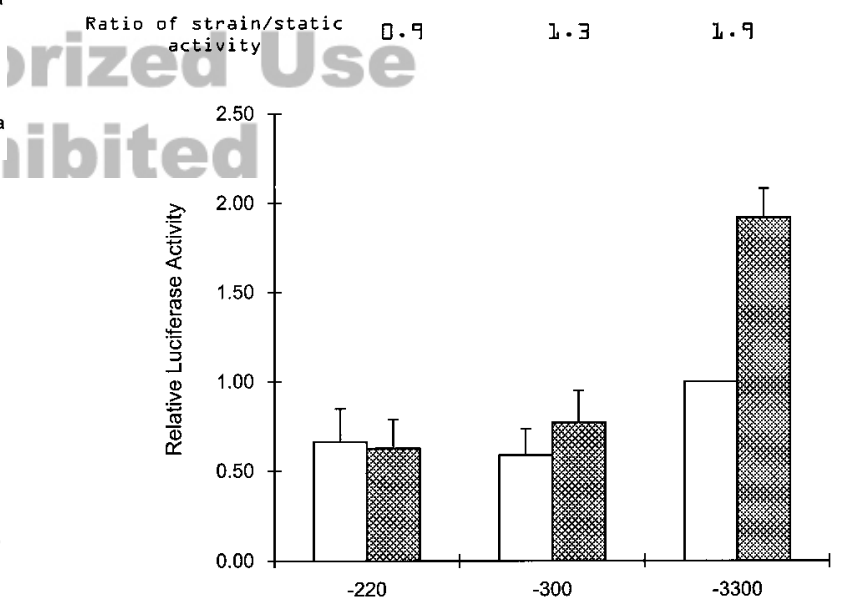

Figure 5.

Transcriptional activities of full-length and truncated MT1-MMP promoterluciferase constructs were tested in unstrained (open bar) and strained (hatched bar) EC. Cyclic strain induces transcriptional activity of MT1-MMP. Overlapping consensus binding sites for Sp1 and Egr-1 contribute to the induction of MT1-MMP in EC subjected to cyclic strain. Results are presented as mean \pm SEM of four independent experiments. 


\section{Cyclic Strain-Induced Endothelial Nuclear Proteins Interact with the Egr-1/Sp1 Binding Site in the MT1-MMP Promoter}

When nuclear extracts from microvascular EC exposed to cyclic strain for 0.5 to 10 hours were incubated with an oligonucleotide whose sequence spans the Egr-1/Sp1 binding site in the MT1-MMP promoter, a gel-shift complex was increased as early as 30 minutes after the application of cyclic strain. However, the complex returned to basal levels by 2 hours (Fig. $6 A)$. The nucleoprotein complex exposed to cyclic strain for 1 hour could be competed with a 50-fold molar excess of the unlabeled oligonucleotide bearing a consensus binding site for Egr-1 and Sp1 but not by the presence of the unlabeled oligonucleotide bearing AP-2 binding sites (Fig. 6B). We next assessed the supershift profiles of nuclear extracts from EC in the unstrained condition and EC exposed to cyclic strain for 1 hour. A gel-shift complex that could be supershifted with an Egr-1 antibody was detectable in nuclear extracts of both EC (Fig. 6C). However, the Egr-1 gel-shift band was much more prominent in the lanes of 1-hour-strained extract. Antibody to Sp1 did not compete with or supershift the gel-shift complexes.

\section{Discussion}

The omnipresent and well-characterized membranetype matrix metalloproteinase, MT1-MMP (also known as MMP-14), is known to have substrate specificity for diverse extracellular matrices including collagens type I and III, fibronectin, and tenascin. MT1-MMP was demonstrated recently to be an effective activator of fibrin, implicating it as an important player in fibrinoIytic cascades (Hiraoka et al, 1998). Despite the correlation between MT1-MMP levels and invasive phe-

A

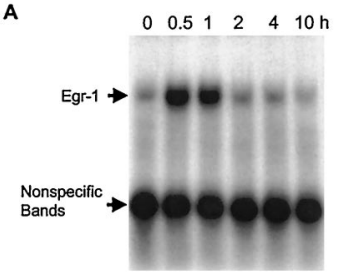

B C
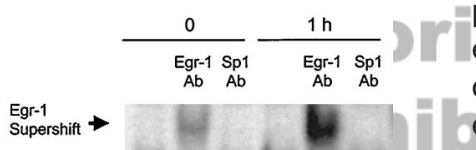

Egr-1 $\rightarrow$ $0 \quad 1 \mathrm{~h}$ $50 \times 50 X$
E/S AP-2 Egr-1 $\rightarrow$

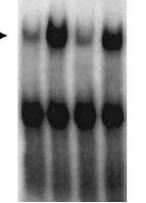

Figure 6.

Gel-shift analysis for Egr-1 and Sp1. A, Time course appearance of a gel-shift complex. Electrophoretic mobility shift assay was performed using nuclear extracts of cells exposed to cyclic strain for $0,0.5,1,2,4$, and 10 hours. B, Competition studies using excess unlabeled oligonucleotides in strained EC for 1 hour. C, Supershift analysis using nuclear extracts of static EC and strained EC for 1 hour. The binding reaction contained 1 to $2 \mu \mathrm{l}$ of the antibody indicated. notype (Sato et al, 1997), vascular tissues have not been well characterized with respect to MT1-MMP expression. Levels of Egr-1, a zinc finger immediateearly response transcription factor, have been demonstrated to be increased in EC upon wounding or increased shear stress or during cyclic mechanical stretching of mesangial cells (Akai et al, 1994; Khachigian et al, 1996; Schwachtgen et al, 1998). In this study, we report that the expression of the immediateearly gene Egr-1 is induced by mechanical cyclic strain and that cyclic strain induces Egr-1-mediated MT1-MMP expression in rat microvascular EC. In our earlier published studies using both in vitro (Haas et al, 1998, 1999) and in vivo (Haas et al, 2000) models of angiogenesis, we have also found this level of induction (2- to 3-fold) of MT1-MMP message and protein. This level of induction was associated with both in vitro and in vivo angiogenesis in our culture and animal models. Inhibition of MT1-MMP activity causes a marked reduction of angiogenesis (by decreasing activation of MMP-2) (Haas et al, 1998, 1999, 2000). In addition, in other studies examining the role of MT1MMP and MMP-2 in T lymphocyte transmigration, we have also found this level of induction of MT1-MMP, which is associated with activation of MMP-2 and enhanced T-cell transmigration (Graesser et al, 1998). Furthermore, in recent studies using our cyclic strain apparatus, we have demonstrated a coordinate induction of MMP-2 message, protein, and activation in EC exposed to the same cyclic strain regimen (our unpublished data). Thus, our experience with several in vitro and in vivo models is consistent with this level of MT1-MMP induction having significant impact on the process of angiogenesis by affecting the activation state of MMP-2.

Egr-1 is a zinc finger transcription factor first identified because of its characteristic immediate-early pattern of expression after exposure of cells to mediators associated with growth and differentiation (Gashler and Sukhatme, 1995; Milbrandt, 1988). It is posited that the transcription factor Egr-1 acts to enhance transcription of MT1-MMP in EC under conditions that involve mechanical stress exerted via the extracellular matrix and that mimic events involved in angiogenesis (Haas et al, 1999). In the latter situation, we previously demonstrated (Haas et al, 1999) that Egr-1 is directly involved because mutations in the Egr-1 binding site abrogated MT1-MMP promoter luciferase activity.

We (Haas et al, 1999) also demonstrated that although transcriptional activity varied with truncations of distal $5^{\prime}$ noncoding regions, the region between -300 and -220 upstream of the initiation site was sufficient to provide both a low level of basal activity in 2-dimensional culture and 2.2-fold enhanced transcriptional activity in 3-dimensional culture. Thus, it was considered to contain the nominal elements necessary to enhance transcription in 3-dimensional stimulated EC. In the present study, EC exposed to cyclic strain increased promoter activity of full-length MT1MMP-luciferase by 1.9 fold and a promoter construct truncated at -300 by 1.3 -fold (Fig. 5). No increase in 
promoter activity was obtained using a promoter construct truncated at -220 . Although the induction is more modest (1.3 versus 2.2), we still consider this region to contain the nominal elements necessary to enhance transcription in cyclic strain-stimulated EC. The difference in levels of induction likely reflects the activation of distinct signaling pathways in these two distinct in vitro culture systems. Because the region between -300 and -220 holds a GC-rich sequence $(-288$ to -275$)$ that contains overlapping consensus binding sites for Sp1 and Egr-1, the findings of the present study are consistent with the hypothesis that Egr-1/Sp1 binding sites contribute to the induction of MT1-MMP in EC exposed to cyclic strain.

Egr-1 is also known to be an important activator for multiple EC genes transcribed during vascular remodeling, including platelet-derived growth factors (PDGF) $A$ and $B$, tissue factor, and transforming growth factor- $\beta$ (Khachigian et al, 1996; Silverman and Collins, 1999). Those studies demonstrated that the promoter from the gene for PDGF-A chain contains a GC-rich element with overlapping binding sites for Egr-1 and Sp1. Under quiescent conditions, these sites are occupied by Sp1, which is believed to be required for basal expression of this gene. In the present study we report that expression of Egr-1 is regulated by cyclic strain.

Our assays detected a faint Egr-1/DNA complex in gel shift in the nuclear extracts from unstrained EC and a prominent Egr-1/DNA complex in the extracts from EC exposed to cyclic strain for 1 hour. This result implies that the amount of Egr-1 present rather than the Sp1 to Egr-1 ratio regulates transcription rate of MT1-MMP in rat microvascular EC, and the increased level of Egr-1 in strained cells results in/enhanced transcription of MT1-MMP. The decrease in Egr-1 complex observed in the presence of anti-Sp1 in static cultures may reflect either a change in Sp1 affinity mediated by anti-Sp1 binding or an accessibility problem for the Egr-1. After 1 hour of cyclic strain, an essentially complete supershift is observed with antiEgr-1, and no appreciable change is noted in the presence of anti-Sp1. These differences between 0 hours and 1 hour of cyclic strain may be a result of the increase in Egr-1 protein, which can now effectively displace Sp1 from the site in the presence (as well as the absence) of anti-Sp1.

It is well established that tractional forces develop within collagen matrices as cells attach, elongate, and migrate (Chicurel et al, 1998; Chiquet et al, 1996; Vernon and Sage, 1995). Three-dimensional collagen matrix-induced MT1-MMP transcriptional activity has been shown to occur as a consequence of increased production and promoter binding of the transcription factor Egr-1 in EC (Haas et al, 1998, 1999). Both cyclic strain and shear stress are hypothesized to trigger angiogenesis in skeletal and coronary muscle in vivo (Hudlicka, 1998), and increased Egr-1 levels are detectable in skeletal muscle under angiogenesispromoting conditions (Michel et al, 1994). Our studies, which show that cyclic strain induces Egr-1-mediated MT1-MMP expression in EC, also support that MT1-
MMP plays an important role in angiogenesis through its activation by hemodynamic forces.

Various reports have demonstrated MT1-MMP expression in some tumor-associated microvessels of advanced human carcinoma tissues (Sato et al, 1997; Ueno et al, 1997). The expression of MT1-MMP and activation of pro-MMP-2 in tumor cells are thought to occur in specialized membrane extensions, called invadopodia (Nakahara et al, 1997). This focal location of MT1-MMP is controlled by the transmembrane and cytoplasmic domains of MT1-MMP. MMP-2 may also be localized on the cell surface of angiogenic EC and melanoma cells by binding to the $\alpha v \beta_{3}$ integrin (Brooks et al, 1996). It has been shown that mRNA and protein levels of both MMP-2 and MT1-MMP elevate significantly after 3 days of chronic electrical stimulation of rat skeletal muscle and that inhibition of MMP activity via the inhibitor GM-6001 correlates with a significant reduction in the number of capillaries with observable breaks in the basement membrane (Haas et al, 2000).

These findings may suggest an importance of MMP expression stimulated by mechanical forces for angiogenesis. It is well known that chronic muscular stimulation elicits angiogenesis. We have recently shown that chronic electrical stimulation of the rodent extensor digitorum longus elicits adaptive angiogenesis that is associated with induction of MT1-MMP. In addition several groups including ours have shown that mechanical stimulation elicits induction of nitric oxide (Awolesi et al, 1995), and nitric oxide has been shown to be a potent modulator of angiogenesis (Papapetropoulos et al, 1997a, 1997b). MMP-2 may also be localized on the cell surface of angiogenic EC and melanoma cells by binding to the $\alpha \mathrm{v} \beta_{3}$ integrin (Brooks et al, 1996).

Overlapping consensus binding sites for Egr-1 and Sp1 are found in the promoters of many other genes thought to be involved in the response to vascular injury or in the development of vascular occlusive disease (Khachigian et al, 1996). Putative nucleotide recognition elements for Egr-1 appear in the promoters of pathophysiologically important genes, including tissue factor (Cui et al, 1994), transforming growth factor- $\beta 1$ (Dey et al, 1994), urokinase-type plasminogen activator (Verde et al, 1988), PDGF-A (Khachigian et al, 1995) and B, (Khachigian et al, 1996), and MT1-MMP (Haas et al, 1999). In this regard, we previously demonstrated that PDGF $B$ transcription and expression is up-regulated in EC exposed to the same cyclic strain regimen (Sumpio et al, 1998).

It has been suggested that the rapid expression of Egr-1 in response to endothelial injury may be consistent with a possible role for this pleiotropic mediator in the regulation of multiple genes involved in vascular remodeling (Khachigian et al, 1996). Our recent report has shown Egr-1-mediated transcription of MT1MMP as a mechanism by which EC can initiate an invasive phenotype in response to an alteration in extracellular matrix environment (Haas et al, 1999). Overlapping consensus binding sites for Egr-1 and Sp1 are also present in the proximal promoters of 
several other endothelial genes whose expression is regulated by cyclic strain. Thus, our demonstration of Egr-1-mediated expression of MT1-MMP by cyclic strain also shows one of the important relations between hemodynamics and pathophysiologic vascular remodeling, and the activation of Egr-1 may be a unifying theme in the induction of various genes in EC subjected to hemodynamic forces.

\section{Materials and Methods}

\section{Cell Culture}

Rat microvascular EC were harvested from the epididymal fat pads of Sprague-Dawley rats and cultured as previously described (Madri and Williams, 1983). Twelve rats were used per preparation, and experiments were performed on two separate isolations of cells. Briefly, cells were grown on gelatin-coated tissue culture plates (1.5\% gelatin in PBS) and maintained in DMEM (Life Technologies, Inc., Rockville, Maryland) containing 25\% sterile-filtered conditioned bovine aortic EC medium and $10 \%$ fetal bovine serum. For all experiments, EC were cultured for 1 to 2 days on type I collagen-coated flexible silicon membrane in a water-jacketed incubator at $37^{\circ} \mathrm{C}$ and $5 \% \mathrm{CO}_{2}$ and then exposed to cyclic strain for up to 24 or 48 hours using the FX 3000 system (Flex-Cell, McKeesport, Pennsylvania). The cyclic strain stimulation was performed at 60 cycles/minute of $24 \%$ maximum strain (150 $\mathrm{mmHg}$ vacuum).

\section{Northern Blot Analysis}

Total cellular RNA was extracted from EC exposed to cyclic strain after solubilizing the cells in TRIzol reagent (Life Technologies, Inc.), according to the manufacturer's instructions. RNA concentration was determined by spectrophotometer. Total RNA (10 or 15 $\mu \mathrm{g})$ was denatured in sample buffer $(20 \mathrm{~mm} 3-\mathrm{N}$ morpholino propane sulfonic acid [MOPS], 6\% formaldehyde, 50\% formamide), electrophoresed through a $1 \%$ agarose-formaldehyde gel, and then transferred to a Nylon Membrane, positively charged (Boehringer Mannheim, Germany) by capillary transfer using $10 \times$ SSC. Hybridization was performed using probes constructed from the Egr-1 expression vector and from human MT1-MMP cDNA, labeled by a random priming Oligolabelling Kit (Amersham Pharmacia Biotech, Piscataway, New Jersey) with $\left[\alpha^{-32}\right.$ P]dCTP (NEN Life Science Products, Inc., Boston, Massachusetts) and purified on Sephadex-G50 columns (Quick Spin Columns, Boehringer Mannheim). Blots were washed using two washes of $1 \times \mathrm{SSC}, 0.1 \% \operatorname{SDS}\left(25^{\circ} \mathrm{C}\right), 0.1 \times$ SSC, $0.1 \%$ SDS $\left(65^{\circ} \mathrm{C}\right)$, and then exposed to X-OMAT AR Film (Kodak, Rochester, New York) for several hours or longer if necessary. Blots were stripped and reprobed with a glyceraldehyde-3-phosphate dehydrogenase probe (American Tissue Culture Center, Manassas, Virginia) to normalize for RNA loading.

\section{Western Blot Analysis}

Cells were lysed in a radioimmune precipitation buffer (0.1\% SDS, $0.5 \%$ sodium deoxycholate, and $1 \%$ Nonidet P-40 in PBS) containing protease inhibitors (Boehringer Mannheim). Lysates were pelleted to remove cellular debris and collagen, and then protein in the supernatant was quantitated using bicinchoninic acid protein assay (Pierce, Rockford, Illinois). Fifteen micrograms of protein/sample were prepared in denaturing conditions and size fractionated in a $10 \%$ SDS-polyacrylamide gel. Gels were blotted onto nitrocellulose membrane. Membranes were blocked for 1 hour $\left(25^{\circ} \mathrm{C}\right)$ in Tris-buffered saline containing $0.5 \%$ Tween 20 and $5 \%$ milk; the proteins of interest were revealed with polyclonal antibodies against MT1-MMP (Chemicon International, Inc., Temecula, California) and Egr-1 (Santa Cruz Biotechnology, Inc., Santa Cruz, California). An affinity-purified polyclonal anti- $\alpha$ actin was used to verify equal protein loading per lane. Horseradish peroxidase-conjugated goat anti-rabbit IgGs and anti-mouse IgGs were used at 1:5000. Enhanced chemiluminescence detection (Amersham Pharmacia Biotech) was performed per the manufacturer's instructions.

\section{DNA Plasmids, Transfections, and Luciferase Assay}

Restriction enzyme-generated fragments of the MT1MMP genomic clone (Sacll site at position -39 as the $3^{\prime}$ end) were subcloned into the pGL3 Basic reporter vector (Promega, Madison, Wisconsin) for use in transient transfection assays. Additional truncation constructs of the MT1-MMP-luciferase constructs were generated using Erase-a-Base (Promega) and sequenced to define the sites of the resultant truncations. Transient transfection routinely used $1 \mu \mathrm{g}$ of MT1-MMP-luciferase constructs and $10 \mu \mathrm{l}$ of LipofectAMINE (Life Technologies, Inc.), diluted in $1 \mathrm{ml}$ of Opti-MEM (Life Technologies, Inc.) according to the manufacturer's protocol. The pSV- $\beta$-galactosidase plasmid was cotransfected to normalize the transfection efficiency. Transfection solution was added to EC, which were cultured on flexible membranes, for 6 hours and then replaced by fresh media. Luciferase activity was measured by using a Lumat 9500 (EG\&G Wallac, Gaithersburg, Maryland). Data were normalized for $\beta$-galactosidase activity and then expressed as fold induction in comparison to the output of the full-length MT1-MMP promoter construct in static EC.

\section{Electrophoretic Mobility Shift Assays}

Consensus Sp1 and Egr-1 binding double-stranded oligonucleotides (synthesized by Oligonucleotide Synthesis Facility, Yale University) of the MT1-MMP promoter were annealed and end-labeled using ( $\left.{ }^{32} \mathrm{P}\right)$ ATP. Nuclear extracts of EC exposed to cyclic strain were prepared using a mini-extraction procedure, with modifications (Pang et al, 1998). EC were washed with PBS and harvested by centrifugation. The pellet was resuspended in $100 \mu \mathrm{l}$ of hypotonic buffer $(10 \mathrm{~mm}$ HEPES, pH 7.9, $10 \mathrm{~mm} \mathrm{KCl,} 0.1 \mathrm{~mm}$ EDTA, $1.5 \mathrm{~mm}$ 
$\mathrm{MgCl}_{2}, 0.5 \mathrm{~mm}$ dithiothreitol, $0.5 \mathrm{~mm}$ phenylmethylsulfonyl fluoride, $1 \times$ complete mixture, $0.5 \mathrm{~mm}$ sodium orthovanadate). After a 15-minute incubation on ice, $25 \mu \mathrm{l}$ of $10 \%$ Nonidet P-40 was added, and the cell suspension was incubated for 5 minutes on ice and then pelleted (700 $\times g$ for 5 minutes). The crude nuclear pellet was resuspended and incubated for 20 minutes in hypertonic solution (20 mM HEPES, pH 7.9, $420 \mathrm{~mm} \mathrm{NaCl}, 0.1 \mathrm{~mm}$ EDTA, $1.5 \mathrm{~mm} \mathrm{MgCl}_{2}, 0.5 \mathrm{~mm}$ dithiothreitol, $0.5 \mathrm{~mm}$ phenylmethylsulfonyl fluoride, $1 \times$ complete mixture, $0.5 \mathrm{~mm}$ sodium orthovanadate). After a 15-minute spin $(14,000 \times g)$, glycerol was added to the supernatant (final concentration, 10\% $[\mathrm{v} / \mathrm{v}]$ ), protein concentration was determined using Bio-Rad Protein Assay (Bio-Rad Laboratories, Inc., Hercules, California), and extracts were used immediately in electrophoretic mobility shift assay reactions or were frozen $\left(-80^{\circ} \mathrm{C}\right)$. Gel-shift reactions consisted of $5 \times 10^{4}$ cycles/minute oligonucleotide probe, binding buffer (10 mM Tris-HCl, pH 7.5, $50 \mathrm{~mm} \mathrm{NaCl}, 1 \mathrm{~mm}$ EDTA, $0.5 \mathrm{~mm}$ dithiothreitol, $10 \%$ glycerol), $1 \mu \mathrm{g}$ of poly(dl-dC), $500 \mathrm{ng}$ of salmon sperm DNA, $1 \mu$ l of TNT reaction (Promega) or recombinant Sp1, or $10 \mu \mathrm{g}$ of cellular lysate. For supershift assays, 1 to $2 \mu \mathrm{l}$ of the appropriate antibody (Santa Cruz Biotechnology, Inc.) was added to the reaction and incubated for 15 minutes before gel loading. Reactions were electrophoresed on a $5 \%$ nondenaturing polyacrylamide gel followed by autoradiography.

\section{Statistics}

Data are presented as mean \pm SEM. Statistical significance for each data set was tested using the paired, two-tailed Student's $t$ test or ANOVA with post-hoc testing where appropriate. Significance level was set at $p<0.05$.

\section{References}

Akai Y, Homma T, Burns KD, Yasuda T, Badr KF, and Harris RC (1994). Mechanical stretch/relaxation of cultured rat mesangial cells induces protooncogenes and cyclooxygenase. Am J Physiol 267(2 Pt 1):C482-C490.

Allen SP, Liang HM, Hill MA, and Prewitt RL (1996). Elevated pressure stimulates protooncogene expression in isolated mesenteric arteries. Am J Physiol 271(4 Pt 2):H1517-H1523.

Awolesi MA, Sessa WC, and Sumpio BE (1995). Cyclic strain upregulates nitric oxide synthase in cultured bovine aortic endothelial cells. J Clin Invest 96:1449-1454.

Birkedal-Hansen H (1995). Matrix metalloproteinases. Adv Dent Res 9(3 Suppl):16.

Brooks PC, Stromblad S, Sanders LC, von Schalscha TL, Aimes RT, Stetler-Stevenson WG, Quigley JP, and Cheresh DA (1996). Localization of matrix metalloproteinase MMP-2 to the surface of invasive cells by interaction with integrin alpha $v$ beta 3. Cell 85:683-693.

Chicurel ME, Chen CS, and Ingber DE (1998). Cellular control lies in the balance of forces. Curr Opin Cell Biol 10:232-239.
Chiquet $\mathrm{M}$, Matthisson $\mathrm{M}$, Koch $\mathrm{M}$, Tannheimer $\mathrm{M}$, and Chiquet-Ehrismann R (1996). Regulation of extracellular matrix synthesis by mechanical stress. Biochem Cell Biol 74: 737-744.

Cui MZ, Parry GC, Edgington TS, and Mackman N (1994). Regulation of tissue factor gene expression in epithelial cells: Induction by serum and phorbol 12-myristate 13-acetate. Arterioscler Thromb 14:807-814.

Davies PF, Barbee KA, Volin MV, Robotewskyj A, Chen J, Joseph L, Griem ML, Wernick MN, Jacobs E, Polacek DC, dePaola N, and Barakat Al (1997). Spatial relationships in early signaling events of flow-mediated endothelial mechanotransduction. Annu Rev Physiol 59:527-549.

Dey BR, Sukhatme VP, Roberts AB, Sporn MB, Rauscher FJ 3rd, and Kim SJ (1994). Repression of the transforming growth factor-beta 1 gene by the Wilms' tumor suppressor WT1 gene product. Mol Endocrinol 8:595-602.

Gashler A and Sukhatme VP (1995). Early growth response protein 1 (Egr-1): Prototype of a zinc-finger family of transcription factors. Prog Nucleic Acid Res Mol Biol 50:191224.

Graesser D, Mahooti S, Haas T, Davis S, Clark RB, and Madri JA (1998). The interrelationship of alpha4 integrin and matrix metalloproteinase-2 in the pathogenesis of experimental autoimmune encephalomyelitis. Lab Invest 78:1445-1458.

Haas TL, Davis SJ, and Madri JA (1998). Three-dimensional type I collagen lattices induce coordinate expression of matrix metalloproteinases MT1-MMP and MMP-2 in microvascular endothelial cells. J Biol Chem 273:3604-3610.

Haas TL, Milkiewicz M, Davis SJ, Zhou AL, Egginton S, Brown MD, Madri JA, and Hudlicka O (2000). Matrix metalloproteinase activity is required for activity-induced angiogenesis in rat skeletal muscle. Am J Physiol Heart Circ Physiol 279:H1540-H1547.

Haas TL, Stitelman D, Davis SJ, Apte SS, and Madri JA (1999). Egr-1 mediates extracellular matrix-driven transcription of membrane type 1 matrix metalloproteinase in endothelium. J Biol Chem 274:22679-22685.

Hanahan D and Folkman J (1996). Patterns and emerging mechanisms of the angiogenic switch during tumorigenesis. Cell 86:353-364.

\section{a) $1=0$}

Hiraoka N, Allen E, Apel IJ, Gyetko MR, and Weiss SJ (1998). Matrix metalloproteinases regulate neovascularization by acting as pericellular fibrinolysins. Cell 95:365-377.

Hudlicka O (1998). Is physiological angiogenesis in skeletal muscle regulated by changes in microcirculation? Microcirculation 5:5-23.

Iba T, Maitz S, Furbert T, Rosales O, Widmann MD, Spillane B, Shin T, Sonoda T, and Sumpio BE (1991). Effect of cyclic stretch on endothelial cells from different vascular beds. Circ Shock 35:193-198.

Khachigian LM, Lindner V, Williams AJ, and Collins T (1996). Egr-1-induced endothelial gene expression: A common theme in vascular injury. Science 271:1427-1431.

Khachigian LM, Williams AJ, and Collins T (1995). Interplay of Sp1 and Egr-1 in the proximal platelet-derived growth factor A-chain promoter in cultured vascular endothelial cells. J Biol Chem 270:27679-27686. 
Madri JA and Williams SK (1983). Capillary endothelial cell cultures: Phenotypic modulation by matrix components. J Cell Biol 97:153-165.

Matrisian LM (1990). Metalloproteinases and their inhibitors in matrix remodeling. Trends Genet 6:121-125.

Michel JB, Ordway GA, Richardson JA, and Williams RS (1994). Biphasic induction of immediate early gene expression accompanies activity-dependent angiogenesis and myofiber remodeling of rabbit skeletal muscle. J Clin Invest 94:277-285.

Mignatti P and Rifkin DB (1996). Plasminogen activators and angiogenesis. Curr Top Microbiol Immunol 213(Pt 1):33-50.

Milbrandt J (1988). Nerve growth factor induces a gene homologous to the glucocorticoid receptor gene. Neuron 1:183-188.

Nakahara H, Howard L, Thompson EW, Sato H, Seiki M, Yeh Y, and Chen WT (1997). Transmembrane/cytoplasmic domain-mediated membrane type 1-matrix metalloprotease docking to invadopodia is required for cell invasion. Proc Natl Acad Sci USA 94:7959-7964.

Osol G (1995). Mechanotransduction by vascular smooth muscle. J Vasc Res 32:275-292.

Pang H, Miranda K, and Fine A (1998). Sp3 regulates fas expression in lung epithelial cells. Biochem J 333(Pt 1):209213.

Papapetropoulos A, Desai KM, Rudic RD, Mayer B, Zhang R, Ruiz-Torres MP, Garcia-Cardena G, Madri JA, and Sessa WC (1997a). Nitric oxide synthase inhibitors attenuate transforming-growth-factor-beta 1-stimulated capillary organization in vitro. Am J Pathol 150:1835-1844.

Papapetropoulos A, Garcia-Cardena G, Madri JA, and Sessa WC (1997b). Nitric oxide production contributes to the angiogenic properties of vascular endothelial growth factor in human endothelial cells. J Clin Invest 100:3131-3139.

Pepper MS (1997). Manipulating angiogenesis: From basic science to the bedside. Arterioscler Thromb Vasc Biol 17: 605-619.

Sato H, Okada Y, and Seiki M (1997). Membrane-type matrix metalloproteinases (MT-MMPs) in cell invasion. Thromb Haemost 78:497-500.

Sato H, Takino T, Okada Y, Cao J, Shinagawa A, Yamamoto E, and Seiki M (1994). A matrix metalloproteinase expressed on the surface of invasive tumour cells [see comments]. Nature 370:61-65.
Schwachtgen JL, Houston P, Campbell C, Sukhatme V, and Braddock M (1998). Fluid shear stress activation of egr-1 transcription in cultured human endothelial and epithelial cells is mediated via the extracellular signal-related kinase $1 / 2$ mitogen-activated protein kinase pathway. J Clin Invest 101:2540-2549.

Silverman ES and Collins T (1999). Pathways of Egr-1mediated gene transcription in vascular biology [comment]. Am J Pathol 154:665-670.

Strongin AY, Collier I, Bannikov G, Marmer BL, Grant GA, and Goldberg Gl (1995). Mechanism of cell surface activation of 72-kDa type IV collagenase: Isolation of the activated form of the membrane metalloprotease. J Biol Chem 270:53315338.

Sumpio BE, editor (1993). Hemodynamic forces and vascular cell biology. Austin, TX: RG Landes Publisher.

Sumpio BE, Banes AJ, Buckley M, and Johnson G Jr (1988). Alterations in aortic endothelial cell morphology and cytoskeletal protein synthesis during cyclic tensional deformation. J Vasc Surg 7:130-138.

Sumpio BE, Du W, Galagher G, Wang X, Khachigian LM, Collins T, Gimbrone MA Jr, and Resnick N (1998). Regulation of PDGF-B in endothelial cells exposed to cyclic strain. Atheroscler Thromb Vasc Biol 18:349-355.

Ueno $\mathrm{H}$, Nakamura $\mathrm{H}$, Inoue M, Imai K, Noguchi M, Sato $\mathrm{H}$, Seiki M, and Okada Y (1997). Expression and tissue localization of membrane-types 1, 2, and 3 matrix metalloproteinases in human invasive breast carcinomas. Cancer Res 57:2055-2060.

Verde P, Boast S, Franze A, Robbiati F, and Blasi F (1988). An upstream enhancer and a negative element in the $5^{\prime}$ flanking region of the human urokinase plasminogen activator gene. Nucleic Acids Res 16:10699-10716.

Vernon RB and Sage EH (1995). Between molecules and morphology: Extracellular matrix and creation of vascular form. Am J Pathol 147:873-883.

Woessner JF Jr (1994). The family of matrix metalloproteinases. Ann N Y Acad Sci 732:11-21. 